\title{
Genetic testing and counselling in Europe: health professionals current educational provision, needs assessment and potential strategies for the future
}

\author{
Domenico A Coviello $^{* 1}$, Heather Skirton ${ }^{2}$, Nadia Ceratto ${ }^{1}$, Celine Lewis ${ }^{3}$ and Alastair Kent ${ }^{3}$ \\ ${ }^{1}$ Laboratory of Medical Genetics, Fondazione IRCCS, Ospedale Maggiore Policlinico, Mangiagalli e Regina Elena, \\ Milan, Italy; ${ }^{2}$ Faculty of Health and Social Work, University of Plymouth, Taunton, UK; ${ }^{3}$ Genetic Interest Group, \\ London, UK \\ European Journal of Human Genetics (2007) 15, 1203-1204; doi:10.1038/sj.ejhg.5201927; published online 26 September 2007
}

The science of genomics is increasingly important to health-care provision in Europe. An estimated 30 million people now suffer from genetic diseases within the enlarged European community. ${ }^{1}$ Increasing numbers of patients are requesting genetic testing and genetic counselling. ${ }^{2}$ A key element in improving the quality of genetic testing services in Europe is the provision of appropriate genetic education for health professionals. This has been shown to be currently inadequate. ${ }^{3-7}$ The objective of this project is to determine needs and potential strategies to educate European health professionals in genetic competences relevant to their professional role.

We collected information about professional education and existing educational material using: (1) a search of the scientific literature, resulting in 36 highly relevant papers, (2) a general internet-based search to identify websites that might include material connected with professional education in genetics and (3) a questionnaire submitted to the chairpersons of professional genetics societies in each European Union country to collect information about national courses and other initiatives in genetics education. The material obtained through the strategies described above was integrated with input from a group of experts who commented both via electronic means and in person at a workshop held in Leuven in December 2005. A database and a report were then generated.

It is clear that genomics will have a significant effect on the practice of medicine, but the extent of the practical impact on patient care is not yet clear. ${ }^{8}$ The findings of our

*Correspondence: Dr DA Coviello, Laboratorio di Genetica Medica, Fondazione IRCCS, Ospedale Maggiore Policlinico, Mangiagalli e Regina Elena, Via Commenda 12, Milano 20122, Italy;

E-mail: d.coviello@policlinico.mi.it study highlight the deficiencies in current provision of education and confirm the need for concerted efforts to provide professional education to a range of health professionals who may play a role in providing genetic testing in the future. However, this is challenging due to the diversity of health-care systems, organizational structures for health professional education and the range of health-care professionals involved in the care of genetic patients across Europe. Competence frameworks have been developed in specific countries to inform the education and training of health professionals in those countries, ${ }^{9,10}$ however, no such framework exists for use across the EU. This is obviously relevant to members of the European Society of Human Genetics (ESHG). The ESHG Education Committee is working collaboratively with other groups (such as the EuroGentest project team) to develop better strategies to facilitate professional education and recognition of all health professionals that work in a genetic setting in Europe. In this context, the project team has begun to address the needs for education and training in Europe by:

1. Improving accessibility to existing resources through creation of an online database of courses offered in Europe [www.Eurogentest.org].

2. Improving access by practitioners to national professional groups and societies through an online list with hyperlinks to relevant organizations [http://www. eurogentest.org/web/info/public/unit6/bodies.xhtml].

3. Creating a Working Group specifically to identify minimum levels of competencies for health-care professionals in Europe and to seek wide consensus on this European document. The aim is to develop competences that enable genetics education to be grounded in clinical contexts that are meaningful to learners ${ }^{8}$ and 
provide the basis for development of learning outcomes and curricula for health professionals in primary, secondary and tertiary care settings.

The full report of this project is available as a PDF on the EuroGentest web page [http://www.eurogentest.org/web/ info/public/unit6/reports.xhtml]. Although the members of the expert group that contributed to this first phase of the project have a broad range of experience and are from a number of EC member states, we are aware that the report may not include all possible information. We are actively seeking feedback and further input from colleagues belonging to various professions and disciplines and for this reason we invite all colleagues willing to contribute to contact us via the EuroGentest web site.

\section{Acknowledgements}

This project was funded by EuroGentest-Network of Excellence, contract no. FP6-512148-2004.

\section{References}

1 Cassiman JJ: EuroGentest-a European Network of Excellence aimed at harmonizing genetic testing services. Eur J Hum Genet 2005; 113: $1103-1105$.
2 Ibarreta D, Elles R, Cassiman JJ, Rodriguez-Cerezo E, Dequeker E: Towards quality assurance and harmonization of genetic testing services in the European Union. Nat Biotechnol 2004; 22: 1230-1235.

3 Lapham EV, Kozma C, Weiss JO, Benkendorf JL, Wilson MA: Between practice and genetic education of health professionals: HuGEM survey results. Genet Med 2000; 2: 226-231.

4 Burke S, Kirk M: Genetics education in the nursing profession: literature review. J Adv Nurs 2006; 54: 228-237.

5 Williams JK: Education for genetics and nursing practice. $A A C N$ Clin Issues 2002; 13: 492-500.

6 Cragun DL, Couch SC, Prows CA, Warren NS, Christianson CA: A success of a genetics educational intervention for nursing and dietetic students: a model for incorporating genetics into nursing and allied health curricula. J Allied Health 2005; 34: 90-96.

7 Challen K, Harris HJ, Julian-Reynier C et al: Genetic education and nongenetic health professionals: educational providers and curricula in Europe. Genet Med 2005; 7: 302-310.

8 Guttmacher AE, Porteous ME, McInerney JD: Educating healthcare professionals about genetics and genomics. Nat Rev 2007; 8: 151-157.

9 NCHPEG: Core Competencies in Genetics Essential for All Health-care Professionals 2005. [http://www.nchpeg.org/core/Corecomps2005. pdf]. Accessed 7 September, 2007.

10 Kirk M, McDonald K, Longley $\mathrm{M}$ et al: Fit for Practice in the Genetics Era: A Competence Based Education Framework for Nurses, Midwives and Health Visitors. Pontypridd: University of Glamorgan, 2003. 